\title{
Relationship between Neuropsychological and Clinical Aspects and Suicide Attempts in Euthymic Bipolar Patients
}

\author{
Relação entre Aspectos Clínicos e Neuropsicológicos e as Tentativas de Suicídio \\ em Pacientes Eutímicos com Transtorno Afetivo Bipolar
}

\author{
Paulo Henrique Paiva de Moraes ${ }^{*}, a$, Fernando Silva Neves ${ }^{a}$, Alina Gomide Vasconcelos ${ }^{a}$, \\ Isabela M. Magalhães Lima ${ }^{b}$, Mayra Brancaglion ${ }^{a}$, Cristina Yumi Sedyiama ${ }^{a}$, Daniel Fuentes ${ }^{c}$, \\ Marco Aurélio Romano-Silva ${ }^{a}$, Humberto Corrêa ${ }^{a} \&$ Leandro Fernandes Malloy-Diniz ${ }^{a}$ \\ ${ }^{a}$ Universidade Federal de Minas Gerais, Belo Horizonte, Brasil, \\ ${ }^{b}$ Instituto Nacional de Ciência e Tecnologia de Medicina Molecular, Belo Horizonte, Brasil \\ $\&{ }^{c}$ Universidade de São Paulo, São Paulo, Brasil
}

\begin{abstract}
Some studies have investigated the possible relationship between suicide attempts and impulsivity in patients with bipolar disorder. The objective of this study was to assess the relationship between neuropsychological and clinical aspects and suicide behavior in euthymic bipolar patients. The Iowa Gambling Task and the Conner's Continuous Performance Test evaluated impulsivity in 95 euthymic bipolar patients -42 suicide attempters and 115 normal control participants. A factorial analysis evaluated the adequacy of the instruments. Furthermore, a multiple regression analysis was done in order to develop a model to predict suicide attempts. Our results point to a specific type of impulsivity related to making decisions, lack of planning and borderline personality disorder comorbidity. This type of impulsivity is a risk factor for suicide attempts in patients with bipolar disorder.

Keywords: Impulsivity, suicidal behavior, bipolar disorder, decision making.

Resumo

Alguns estudos investigaram a possível relação entre tentativas de suicídio e impulsividade em pacientes com transtorno bipolar. O objetivo do estudo foi avaliar a relação entre características neuropsicológicas e clínicas e o comportamento suicida em pacientes bipolares eutímicos. Utilizamos o Iowa Gambling Task e o Conner's Continuous Performance Test para avaliar a impulsividade em 95 pacientes eutímicos com transtorno bipolar (42 com tentativas de suicídio) e 155 controles normais. Uma análise fatorial avaliou a adequação dos instrumentos e foi criado um modelo para previsão do número de tentativas de suicídio usando regressão linear múltipla. Nossos resultados apontam para um tipo específico de impulsividade relacionada à tomada de decisões, falta de planejamento e para a comorbidade Transtorno de Personalidade Borderline. A impulsividade por não planejamento é um fator de risco para tentativas de suicídio em pacientes com Transtorno Bipolar.

Palavras-chaves: Impulsividade, suicídio, transtorno bipolar, tomada de decisão.
\end{abstract}

Impulsivity is a clinical manifestation present in many psychiatric disorders, including antisocial personality disorder, borderline personality disorder, substance abuse/dependence, attention-deficit/hyperactivity disorder and bipolar disorder (Hollander \& Evers, 2001; Moeller, Barratt, Dougherty, Schmitz, \& Swann, 2001). The impul-

\footnotetext{
"Endereço para correspondência: Faculdade de Medicina, Departamento de Psiquiatria e Neurologia, Universidade Federal de Minas Gerais, Av. Prof. Alfredo Balena, 190, Belo Horizonte, MG, Brasil 30130-100. Tel.: (31) 3409 9753. E-mail: paulohpmoraes@gmail.com, fneves.bhz@terra.com.br, alinagomide@gmail.com, isabelammlima@gmail.com, mayrayara@gmail.com, cristinayumi@hotmail.com, dfuentes@usp.br, romanosilva@gmail.com,correa@task.com.br e malloy.diniz@gmail.com
}

sive phenotype is a complex and multifaceted pattern of behavior and several neuropsychiatric disorders included in the DSM-IV presents some type of impulsive manifestation (Evenden, 1999; Moeller et al., 2001).

Moeller et al. (2001) defined impulsivity as "a predisposition toward rapid, unplanned reactions to internal or external stimuli without regard to the negative consequences of these reactions to the impulsive person or to others". The hypothesis that different types of impulsive behavior exist is in agreement with neurobiological (Pattij \& Vanderschuren, 2008), neuropsychological (Bechara \& Linden, 2005) and psychological studies (Stanford et al., 2009). For instance, Barratt's model of impulsivity considers three main impulsive subtraits: motor impulsivity (acting without thinking); attentional impulsivity (lack of 
concentration); and non-planning impulsivity (orientation toward the present rather than the future; Patton, Stanford, \& Barratt, 1995). Using these dimensions of impulsivity, Swann, Steinberg, Lijffijt and Moeller (2008) concluded that the distinct aspects of impulsivity appear to be differentially related to depressive and manic symptoms. Increased motor impulsivity is correlated with mania, and non-planning impulsivity is correlated with depression, whereas attentional impulsivity is correlated with both depression and mania.

Bipolar disorder (BD) is a severe affective syndrome characterized by a cyclical pattern of mood changes (e.g., depression, mania/hypomania and euthymia) and a high likelihood of comorbidity with other disorders. Roughly $1.3 \%$ to $1.6 \%$ of the population will be diagnosed with $\mathrm{BD}$ at some point of their lifetime (Müller-Oerlinghausen, Berghöfer, \& Bauer, 2002). The association between BD and impulsivity is not restricted to single episodes of mood-related illness; they are also present within euthymic phases of the disorder (Moeller et al., 2001). The most deleterious consequence of BD is suicidality: onethird of patients acknowledge attempting suicide at least once, and approximately $10 \%$ to $20 \%$ of patients successfully commit suicide (Müller-Oerlinghausen et al., 2002). Suicide prevention strategies are currently based on screening for the numerous risk factors. For instance, there are evidences that comorbidity with alcoholism and/ or with borderline personality disorders increase the risk for suicide attempts in bipolar patients (Neves, Corrêa, \& Malloy-Diniz, 2009; Oquendo et al., 2010). Unfortunately, no risk factor alone has sufficient predictive power (Galfalvy, Huang, Oquendo, Currier, \& Mann, 2009; Jollant et al., 2005).

Some authors assume that there is a relationship between impulsivity and suicide (Turecki, 2005); however, impulsivity is a complex construct, and there are many ways to define and measure it, which leads to differences in the results. Furthermore, because impulsivity might comprise different dimensions with distinct neuroanatomical and functional substrates (Bechara \& Linden, 2005; Patton et al., 1995), assessing the relationship among these different impulsive manifestations and suicidality is important. Therefore, this study seeks to characterize the relationship between the different dimensions of impulsivity and suicidality in patients with BD considering its comorbidities. In particular, we aim to test the hypothesis that a specific type of impulsive pattern (decision making and lack of planning) is related to suicide behavior, regardless of the types of impulsive behavior related to inhibitory control and attention management as suggested by our previous studies (Malloy-Diniz, Neves, Abrantes, Fuentes, \& Corrêa, 2009). We consider of particular interest in our study, the assessment of a probably association between Borderline Personality Disorder and suicide attempts in Bipolar Disorder patients since Borderline Disorder itself is characterized by impulsive behavior and increases the risk for suicide attempt (American Psychiatric Association [APA], 1994). Furthermore, in a previous study we found that bipolar disorder patients who present the comorbid Borderline Personality Disorder are more prone to violent suicide attempts (Neves et al., 2009).

\section{Method}

\section{Participants}

Ninety-five outpatients with bipolar disorder (mean age 40.94, $S D=12.380$ ) from Clinical Hospital of Universidade Federal de Minas Gerais, Brazil. Forty-two patients $(44.2 \%)$ had a history of at least one suicide attempt. Twenty-three patients $(24.2 \%)$ had also borderline personality disorder, 18 of them (78.3\%) with history of previous suicide attempts. A psychiatrist performed a BD diagnosis (Type I or II, according to DSM-IV criteria) using the MINI Plus v. 5.0 structured interview (Amorim, 2000). To diagnose psychiatric comorbidities, we also used the MINI Plus v. 5.0 DSM-IV-TR criteria considering axis I disorders. Structured Clinical Interview for DSMIV - SCID-II (Del-Ben, Rodrigues, \& Zuardi, 1996) - was used to assess Borderline Personality, since this disorder is closely related to both suicide attempts and impulsive behavior (da Rocha, Malloy-Diniz, de Sousa, et al., 2008; Neves et al., 2009). We further assessed all patients using the Beck Depression Inventory (BDI) and the Young Mania Rating Scale (YMRS). All patients had euthymic mood on the assessment day if they scored lower than 12 points on the BDI and lower than 13 on the YMRS.

We recruited 115 control participants (mean age 31.25, $S D=12.72$ ) from the community via an advertisement. We screened controls for any psychiatric condition using the MINI Plus v. 5.0. None of these participants showed a history of psychiatric illness or suicidality (exclusion criteria).

For both patients with BD and healthy controls, additional inclusion criteria consisted of at least 8 years of formal education and intelligence scores, measured with Raven Progressive Matrices, within two $S D$ of the population mean. No participant had a history of traumatic brain injury or aneurysm.

\section{Instruments}

As in our previous studies (Malloy-Diniz, Fuentes, Leite, Corrêa, \& Bechara, 2007; da Rocha, Malloy-Diniz, Lage, et al., 2008), we used two neuropsychological tests (the CPT-II and IGT) to assess different types of impulsive behavior. The rationale for using these two measures is based on the evidence that the dorsolateral prefrontal cortex and the orbitofrontal prefrontal cortex are related to different types of impulse control (Bechara \& Linden, 2005). The former is related to those aspects of impulsive behavior that encompass inhibitory control. The latter is related to decision making and future-oriented behavior 
(Bechara, H. Damasio, \& A. R. Damasio, 2000; MalloyDiniz et al., 2007).

Continuous Performance Test II (CPT-II). The CPT-II is a computerized test in which the participant presses the spacebar when any letter (except X) appears on screen. An omission error occurs when the participant fails to press the spacebar (fails targeted response). A commission error occurs when the participant presses the spacebar to an X (fails to inhibit pre-potent motor response). Reaction time (RT) - defined as the time elapsed between the stimulus presentation and the participant's response - was measured for all valid responses.

Iowa Gambling Task (IGT). On the IGT (Bechara, Tranel, \& H. Damasio, 2000), participants must choose one card at a time from four decks labeled A, B, C and D. The task requires that participants complete 100 trials. In each trial, participants either win money or, sometimes unpredictably, they lose money. Two decks (A and B) yield relatively high immediate gains (i.e., $\$ 100$ per trial). In the long run, however, they incur high losses; thus, these decks are disadvantageous. The other decks (C and D) yield relatively lower gains (i.e., $\$ 50$ per trial) but incur smaller losses in the long run; thus, these decks are advantageous. Over many trials, normal participants learn to avoid decks A and B in favor of C and D. IGT performance is measured by dividing the 100 trials into five blocks of 20 trials each. For each block, the sum of good choices is subtracted from the sum of bad choices (i.e., $[\mathrm{C}+\mathrm{D}]-[\mathrm{A}+\mathrm{B}])$, which results in a score for that block. A net score is obtained by adding all block scores. We used a computerized version of the IGT validated for Brazilians (Malloy-Diniz et al., 2008). The five block scores (B1 to B5) are a measure of decision making-related impulsivity.

\section{Procedure}

As in our past work (Neves et al., 2008), we assessed patients' suicide attempt histories using a semi-structured interview and another interview with a close family member. We also reviewed patients' medical records. All participants underwent a neuropsychological impulsivity assessment consisting of Conner's Continuous Performance Task II (Conners, Epstein, Angold, \& Klaric, 2003) and the Iowa Gambling Test (Bechara, A. R. Damasio, H. Damasio, \& Anderson, 1994; Malloy-Diniz et al., 2008). Fully trained neuropsychologists conducted the assessment. The Local Ethics Review Committee approved the study protocol. All participants signed informed consent statements prior to participating in this study. This research is in accordance with the Helsinki Declaration as revised 1989. We compared the demographic characteristics and neuropsychological assessment results between groups (i.e., patients with $\mathrm{BD}$ versus controls, patients with BD and a history of suicidality versus patients with BD without said history of suicidality and patients with $\mathrm{BD}$ and borderline personality disorder versus those without borderline personality disorder).
Statistical Analyses

To compare demographic characteristics and neuropsychological results between groups, we used chisquared test and Mann-Whitney $U$ test. To compare the presence or absence of comorbidities between patients with BD and a history (or not) of suicidality, we used chi-squared test. We considered all differences less than $\alpha=.05$ to be significant.

A factorial analysis evaluated the assessment adequacy of the different impulsivity dimensions. As in a previous study (Malloy-Diniz et al., 2007), we used the results obtained from the CPT-II (omission and commission errors as well as RT) and the IGT (Blocks 1 through 5) as impulsivity measures. The results for all participants were submitted to an exploratory principal component analysis using an extraction method and Quartimax rotation with Kaiser normalization using SPSS 17.0.

Finally, a multiple regression analysis assessed comorbidity and impulsivity factors in relation to suicide attempt history. Using patients with BD and a history (or not) of suicide attempts, the first model predicted the relationship between the various independent variables and the number of suicide attempts (dependent variable), with a significance level set at $\alpha=.05$. This multiple regression analysis used the Enter method from SPSS 17.0 and a step-by-step manual reduction. The first model included all independent variables with significant correlation $(p<.05)$ to the dependent variable. The variables that had no significant contribution to the model were removed using backward selection. We repeated this procedure until all independent variables that did not fulfill the significance criteria were removed.

\section{Results}

There were no gender or educational differences between the control group and patients with BD. Considering psychiatric comorbidities, patients showed a higher frequency of Generalized Anxiety Disorder (56.8\%) and moderate frequency of Borderline Personality Disorder (24.2\%). Furthermore, $47.4 \%$ were smokers.

Bipolar patients had a significantly poorer performance on all impulsivity measures compared to the control group. Furthermore, bipolar patients with a history of suicide attempts when compared to BD without history of suicide attempt were more frequently diagnosed with borderline personality disorder, alcoholism and nicotine addiction comorbidities as well as showed worse performance on neuropsychological measures related to decision making and non-planning impulsivity (IGT Blocks 3 and 5, netscore and Factor 1 of the factorial analysis) compared to patients with BD but without a history of suicidality. Tables 1 and 2 summarize all between-group statistics. 
Moraes, P. H. P., Neves, F. S., Vasconcelos, A. G., Lima, I. M. M., Brancaglion, M., Sedyiama, C. Y., Fuentes, D., Romano-Silva, M. A., Corrêa, H. \& Malloy-Diniz, L. F.(2013). Relationship between Neuropsychological and Clinical Aspects and Suicide Attempts in Euthymic Bipolar Patients.

Table 1

Statistics for Controls and BD Patients

\begin{tabular}{lcccc}
\hline & Controls $(n=115)$ & BD patients $(n=95)$ & \multirow{2}{*}{$z$ or $\chi^{2}$} & $p$ \\
\cline { 2 - 4 } & Freq. (\%) or Mean $(S D)$ & Freq. (\%) or Mean $(S D)$ & & \\
\hline Age (years) & $31.25(12.72)$ & $40.94(12.38)$ & -5.40 & .00 \\
Sex (female) & $73(63.5)$ & $65(68.4)$ & .56 & .45 \\
Education (college) & $55(47.8)$ & $31(32.6)$ & 14.14 & .00 \\
Marital Status (Single) & $72(62.6)$ & $39(41.1)$ & 13.93 & .00 \\
Intelligence & $-.25(.99)$ & $-.22(.71)$ & -1.78 & .07 \\
BDI & $6.21(3.63)$ & $9.64(4.68)$ & -2.98 & .00 \\
YMRS & $.36(1.29)$ & $7.41(4.78)$ & -6.58 & .00 \\
IGT Block 1 & $-1.68(6.05)$ & $-1.92(4.30)$ & -.11 & .91 \\
IGT Block 2 & $1.72(6.53)$ & $.37(5.05)$ & -.99 & .28 \\
IGT Block 3 & $4.96(6.97)$ & $1.45(6.93)$ & -3.91 & .00 \\
IGT Block 4 & $6.03(7.80)$ & $1.93(7.38)$ & -3.53 & .00 \\
IGT Block 5 & $5.89(8.37)$ & $1.77(8.93)$ & -3.33 & .00 \\
IGT Net Score & $16.91(23.49)$ & $3.91(24.22)$ & -3.75 & .00 \\
CPT Omissions & $4.12(5.67)$ & $10.06(16.25)$ & -4.59 & .00 \\
CPT Comissions & $11.25(7.72)$ & $16.13(8.53)$ & -4.08 & .00 \\
CPT RT (ms) & $386.61(72.15)$ & $429.68(89.45)$ & -3.94 & .00 \\
Factor 1 (Inp) & $.22(.96)$ & $-.29(.99)$ & -3.70 & .00 \\
Factor 2 (I) & $-.23(.66)$ & $.354(1.26)$ & -5.05 & .00 \\
Factor 3 (I $\mathrm{I}_{\mathrm{m}}$ ) & -5.07 & $.19(.93)$ & -2.49 & .01 \\
\hline
\end{tabular}

Note. BDI - Beck depression inventory; YMRS - Young mania rating scale; RPM - Raven's progressive matrices; IGT - Iowa gambling task; CPT - Conner's continuous performance test; RT - Reaction time.

a $z$-score on Raven's progressive matrices.

Table 2

Statistics for Bipolar Patients With and Without History of Suicide Attempt

\begin{tabular}{|c|c|c|c|c|}
\hline & Suicide attempters $(n=42)$ & Non attempters $(n=53)$ & $z$ or $\chi^{2}$ & $p$ \\
\hline & Freq. $(\%)$ or Mean $(S D)$ & Freq. $(\%)$ or Mean $(S D)$ & & \\
\hline Age (years) & $39.6(13.30)$ & $42.0(11.61)$ & -1.18 & .23 \\
\hline Sex (female) & $31(73.8)$ & $34(64.2)$ & 1.01 & .31 \\
\hline Education (college) & $13(31.0)$ & $18(34.0)$ & .97 & .76 \\
\hline Marital Status (Single) & $19(45.2)$ & $18(34.0)$ & 3.57 & .31 \\
\hline BD (Type I) & $28(66.7)$ & $27(50.9)$ & 2.38 & .12 \\
\hline GAD & $26(61.9)$ & $28(52.8)$ & .78 & .37 \\
\hline Panic disorder & $8(19.0)$ & $9(17.0)$ & .06 & .79 \\
\hline $\mathrm{BPD}$ & $18(42.9)$ & $5(9.4)$ & 14.26 & .00 \\
\hline Alcohol abuse & $17(40.5)$ & $11(20.8)$ & 4.38 & .04 \\
\hline Nicotine addiction & $19(35.8)$ & $26(61.9)$ & 6.38 & .01 \\
\hline Substance abuse & $5(11.9)$ & $7(13.2)$ & .04 & .85 \\
\hline Psychotic disorder & $14(33.3)$ & $11(20.8)$ & 1.91 & .17 \\
\hline Eating disorder & $4(9.5)$ & $1(1.9)$ & 2.74 & .10 \\
\hline $\mathrm{OCD}$ & $3(7.1)$ & $2(3.8)$ & .53 & .46 \\
\hline Intelligence $^{\mathrm{a}}$ & $-.165(.782)$ & $-.268(.65)$ & -.77 & .44 \\
\hline BDI & $9.71(4.044)$ & $9.58(5.16)$ & -1.19 & .23 \\
\hline YMRS & $7.90(4.684)$ & $7.02(4.83)$ & -.99 & .32 \\
\hline IGT Block 1 & $-2.62(4.622)$ & $-1.36(3.98)$ & -.87 & .38 \\
\hline IGT Block 2 & $-.95(4.864)$ & $1.42(4.98)$ & -1.95 & .05 \\
\hline IGT Block 3 & $-.95(5.847)$ & $3.36(7.18)$ & -3.31 & .00 \\
\hline IGT Block 4 & $.19(7.775)$ & $3.30(6.81)$ & -1.89 & .06 \\
\hline IGT Block 5 & $-1.05(8.914)$ & $4.00(8.38)$ & -2.95 & .00 \\
\hline
\end{tabular}




\begin{tabular}{lcccc} 
IGT Net Score & $-3.90(23.453)$ & $10.09(23.20)$ & -2.89 & .00 \\
CPT Omissions & $8.81(8.66)$ & $11.06(20.40)$ & -.85 & .39 \\
CPT Comissions & $16.79(8.64)$ & $15.60(8.48)$ & -.56 & .57 \\
CPT RT $(\mathrm{ms})$ & $426.54(88.33)$ & $432.17(91.03)$ & -.09 & .92 \\
Factor 1 $\left(\mathrm{I}_{\mathrm{np}}\right)$ & $-.65(.98)$ & $-.01(.92)$ & -3.29 & .00 \\
Factor 2 $(\mathrm{I})$ & $.25(.92)$ & $.44(1.47)$ & -.45 & .66 \\
Factor 3 $\left(\mathrm{I}_{\mathrm{m}}\right)$ & $.24(.94)$ & $.16(.94)$ & -.38 & .71 \\
\hline
\end{tabular}

Note. GAD - Generalized anxiety disorder; BPD - Borderline personality disorder; OCD - Obsessive compulsive disorder; BDI - Beck depression inventory; YMRS - Young mania rating scale; RPM - Raven's progressive matrices; IGT - Iowa gambling task; CPT - Conner's continuous performance test; RT - Reaction time.

a $z$-score on Raven's progressive matrices.

Table 3 shows the factor analysis that resulted in three components. Blocks 2 through 5 of the IGT formed Factor 1, which was defined as "decision-making impulsivity." Good performance on this task relies on the ability to plan long term. Low scores on these blocks reflect the inability to make decisions regarding the future. As expected, Block 1 was not included in Factor 1 because the first 20 choices were mostly randomized and exploratory. Factor
2 comprised CPT-II omission errors and RT. This factor was associated with attention impulsivity. Increases in omission errors and reaction time reflected distraction moments (i.e., when his or her focus is deflected momentarily). Finally, Factor 3 comprised CPT-II commission errors and reflected responses evoked before a correct response. Factor 3 was associated with inhibitory control.

Table 3

Rotated Components Matrix of the Factorial Analysis

\begin{tabular}{lccc}
\hline & & Components & Factor 3 $\left(\mathrm{I}_{\mathrm{m}}\right)$ \\
\cline { 2 - 4 } & Factor 1 $\left(\mathrm{I}_{\mathrm{np}}\right)$ & Factor 2 $\left(\mathrm{I}_{\mathrm{c}}\right)$ & -.558 \\
\hline IGT B1 & .105 & .058 & -.036 \\
IGT B2 & .681 & .034 & -.1104 \\
IGT B3 & .814 & -.037 & -.195 \\
IGT B4 & .826 & -.008 & .044 \\
IGT B5 & .795 & -.083 & .292 \\
CPT Omissions & -.033 & .842 & .828 \\
CPT Comissions & -.152 & .103 & -.252 \\
CPT RT & -.075 & .855 & \\
\hline
\end{tabular}

Note. Extraction Method: Principal Component Analysis. Rotation Method: Quartimax with Kaiser Normalization. Rotation converged in 4 iterations.

Presence of comorbid borderline personality disorder and decision-making/non-planning impulsivity were the independent variables remaining after the multiple regression analysis $(F=21.120 ; p<.001$; Table 4$)$. This model explained $31.5 \%\left(R^{2}\right.$ adjusted $\left.=.315\right)$ of the variability of suicidality in our sample.

Table 4

Coefficients Variables Resulting from Multiple Regression Analysis

\begin{tabular}{lccccc}
\hline & \multicolumn{2}{c}{$\begin{array}{c}\text { Unstandardized } \\
\text { Coefficients }\end{array}$} & $\begin{array}{c}\text { Standardizes } \\
\text { Coefficients }\end{array}$ & & \\
\cline { 2 - 6 } & $\mathrm{B}$ & Std. Error & Beta & $t$ & Sig. \\
\hline Constant & .555 & .184 & & 3.022 & .003 \\
Borderline personality disorder & 1.875 & .364 & .445 & 5.148 & .000 \\
Factor 1 (I Inp ) & -.587 & .158 & -.321 & -.721 & .000
\end{tabular}

Note. Dependent variable: number of suicide attempts. 
Moraes, P. H. P., Neves, F. S., Vasconcelos, A. G., Lima, I. M. M., Brancaglion, M., Sedyiama, C. Y., Fuentes, D., Romano-Silva, M. A., Corrêa, H. \& Malloy-Diniz, L. F.(2013). Relationship between Neuropsychological and Clinical Aspects and Suicide Attempts in Euthymic Bipolar Patients.

\section{Discussion}

The results of this study corroborate previous research and point to the possibility of neuropsychological deficits in impulsive patients with bipolar disorder (Olley et al., 2005; Selva et al., 2007). In particular, this finding agrees with our previous study that used a sample of outpatients with bipolar I disorder (Malloy-Diniz et al., 2009) where we found that patients with $\mathrm{BD}$ were more prone to impulsive results on the CPT-II and the IGT compared to healthy controls.

The BD group was not different from the control group on any of the sociodemographic variables studied except age: patients with $\mathrm{BD}$ were older than controls. However, this difference did not affect the results: despite the age difference, control and bipolar group mean ages were both within middle adulthood. Therefore, this difference did not likely affect the impulsivity results (Zelazo, Craik, $\&$ Booth, 2004). Furthermore, age did not fit in the best regression model.

We found three independent factors in the factorial analysis of the impulsivity assessment. The first factor encompassed the last four IGT blocks and was related to making decisions. The second factor involved both CPT-II omission errors and reaction time and was related to attention functions. The last factor comprised the first IGT block as well as CPT-II commission errors and was related to either an inhibitory control deficit or a motor type of impulsivity associated with both environment exploration and response inhibition. The factors founded in this study are similar to those described in Barratt (Patton et al., 1995), Bechara (2005) and Bechara, Tranel, et al. (2000). Considering the multidimensional nature of impulsive behavior, Barratt arghes that it comprises three components: motor (action without thinking), lack of attention (on the task) and non planning (orientation toward the present rather than toward the future). Likewise, Bechara states that there are functional and structural differences among motor impulsivity (lack of the ability to inhibit an immediate response), making decisions (analogous to Barratt's non-planning impulsivity) and another type of impulsivity related to attention and working memory (lack of the ability to inhibit irrelevant information and focus on the task at hand). Attentional and motor impulsivity may be related to the dopaminergic fronto-striatal system (Sagvolden, Johansen, Aase, \& Russell, 2005). Impulsivity related to making decisions has been linked to the orbitofrontal and ventromedial areas of the prefrontal cortex (Sagvolden et al., 2005) and may be more sensitive to the modulation of the serotonergic system (Rogers et al., 2003). Because prefrontal dysfunctions encompassing different neural regions and circuits have been related to patients with BD (Matsuo et al., 2009; Mazzola-Pomietto, Kaladjian, Azorin, Anton, \& Jeanningros, 2009), the present finding demonstrating that different kinds of impulsive behaviors exist in these patients is not unexpected. The association between the three factors obtained in our study and those described by Barratt should be investigated in future studies.

Previous studies have reported that impulsive behavior is related to depressive and manic episodes in patients with BD. Swann, Lijffijt, Lane, Steinberg and Moeller (2009) found that BIS-11 scores are differentially related to mood states in patients with BD such that motor impulsiveness is related to mania, non-planning impulsiveness is related to depression and attentional impulsiveness is related to both. In the present study, we found that these three types of impulsivity also exist in patients during euthymic states, which reinforces the idea that impulsivity is a trait that is present in patients with $\mathrm{BD}$ regardless of affective status.

An important finding in this study is the relationship between impulsivity and comorbidities in patients with BD with a history of suicide attempts. As previously mentioned, research has demonstrated the relationship between impulsiveness and suicidality (Turecki, 2005). This research also found that only the decision-making factor was related to a history of suicide attempts, concordant with previous studies (Jollant et al., 2005; MalloyDiniz et al., 2009; Swann et al., 2005); furthermore, it suggests the possibility that impulsivity-related decisionmaking has an important role to suicidality. In addition, non-planning impulsiveness is related to an orientation on the present instead of the future. According to Swann et al. (2008), the relationship between hopelessness and impulsiveness may be a risk factor for suicidality.

The present study suggests that the best predictor of suicidality is decision-making impulsivity in $\mathrm{BD}$ comorbid with borderline personality disorder. Borderline personality disorder is an important risk factor for suicide in bipolar disorder (Rihmer \& Benazzi, 2010). Furthermore, impulsivity is an important predictor of suicide behavior in borderline personality disorder (Neves et al., 2009) and bipolar disorder. Therefore, our results suggest the existence of a bipolar disorder subgroup, comprising people with high levels of decision-making impulsivity and borderline personality disorder comorbidity wich has a higher risk for suicidality.

The current study has several limitations. The sample size was small, which reduces the statistical power of our analyses when conducting comparisons between suicide attempters and non-attempters on the impulsivity measures. This limitation might have affected our comorbidity effect findings. Therefore, future studies should explore the effect of BD and making decisions using a larger sample. Another limitation is that all participants with BD were undergoing pharmacological therapy during the research and these treatments may have influenced our study results (we could not stop medications for ethical reasons); however, according to Ancín et al. (2010), cognitive alterations in patients with $\mathrm{BD}$ cannot be explained by medication because most changes remained after 
statistically controlling for medication in several studies (Fleck, Sax, \& Strakowski, 2001). The same was true for drug-free patients with BD during euthymic states (Goswami et al., 2009).

Despite these limitations, to the best of our knowledge, this is the first study to assess the association between non-planning impulsivity, borderline personality disorder and the number of suicide attempts in the lifetime of patients with bipolar disorder during a euthymic phase. The relationship between impulsivity in patients with BD and suicidal behavior and impulsivity's probable role as an endophenotype should be investigated further.

\section{References}

American Psychiatric Association. (1994). DSM-IV: Diagnostic and statistical manual of mental disorder ( $4^{\text {th }} \mathrm{ed}$.). Washington, DC: Author.

Amorim, P. (2000). Mini International Neuropsychiatric Interview (MINI): Validação de entrevista breve para diagnóstico de transtornos mentais. Revista Brasileira de Psiquiatria, 22(3), 106-115.

Ancín, I., Santos, J. L., Teijeira, C., Sánchez-Morla, E. M., Bescós, M. J., Argudo, I., et al. (2010). Sustained attention as a potential endophenotype for bipolar disorder. Acta Psychiatrica Scandinavica, 122(3), 235-245.

Bechara, A. (2005). Decision making, impulse control and loss of willpower to resist drugs: A neurocognitive perspective. Nature Neuroscience, 8(11), 1458-1463.

Bechara, A., Damasio, A. R., Damasio, H., \& Anderson, S. W. (1994). Insensitivity to future consequences following damage to human prefrontal cortex. Cognition, 50(1-3), 7-15.

Bechara, A., Damasio, H., \& Damasio, A. R. (2000). Emotion, decision making and the orbitofrontal cortex. Cerebral Cortex, 10(3), 295-307.

Bechara, A., \& Linden, M. V. D. (2005). Decision-making and impulse control after frontal lobe injuries. Current Opinion in Neurology, 18(6), 734-739.

Bechara, A., Tranel, D., \& Damasio, H. (2000). Characterization of the decision-making deficit of patients with ventromedial prefrontal cortex lesions. Brain, 123(Pt. 11), 2189-2202.

Conners, C. K., Epstein, J. N., Angold, A., \& Klaric, J. (2003). Continuous Performance Test Performance in a Normative Epidemiological Sample. Journal of Abnormal Child Psychology, 31(5), 555-562.

da Rocha, F. F., Malloy-Diniz, L., de Sousa, K. C. A., Prais, H. A. C., Correa, H., \& Teixeira, A. L. (2008). Borderline personality features possibly related to cingulate and orbitofrontal cortices dysfunction due to schizencephaly. Clinical Neurology and Neurosurgery, 110(4), 396-399.

da Rocha, F. F., Malloy-Diniz, L., Lage, N. V., Romano-Silva, M. A., Marco, L. A. de, \& Corrêa, H. (2008). Decision-making impairment is related to serotonin transporter promoter polimorphism in a sample of patients with obsessive-compulsive disorder. Behavioral Brain Research, 195, 159-163.

Del-Ben, C. M., Rodrigues, C. R., \& Zuardi, A. W. (1996). Reliability of the Portuguese version of the structured clinical interview for DSM-III-R (SCID) in a Brazilian sample of psychiatric outpatients. Brazilian Journal of Medical and Biological Research, 29(12), 1675-1682.
Evenden, J. L. (1999). Varieties of impulsivity. Psychopharmacology, 146, 348-361.

Fleck, D. E., Sax, K. W., \& Strakowski, S. M. (2001). Reaction time measures of sustained attention differentiate bipolar disorder from schizophrenia. Schizophrenia Research, 52(3), 251-259.

Galfalvy, H., Huang, Y.-Y., Oquendo, M. A., Currier, D., \& Mann, J. J. (2009). Increased risk of suicide attempt in mood disorders and TPH1 genotype. Journal of Affective Disorders, 115(3), 331-338.

Goswami, U., Sharma, A., Varma, A., Gulrajani, C., Ferrier, I. N., Young, A. H., et al. (2009). The neurocognitive performance of drug-free and medicated euthymic bipolar patients do not differ. Acta Psychiatrica Scandinavica, 120(6), 456463.

Hollander, E., \& Evers, M. (2001). New Developments in Impulsivity. The Lancet, 358(9286), 949-950.

Jollant, F., Bellivier, F., Leboyer, M., Astruc, B., Torres, S., Verdier, R., et al. (2005). Impaired decision making in suicide attempters. American Journal of Psychiatry, 162(2), 304310 .

Malloy-Diniz, L., Fuentes, D., Leite, W. B., Corrêa, H., \& Bechara, A. (2007). Impulsive behavior in adults with attention deficit/hyperactivity disorder: Characterization of attentional, motor and cognitive impulsiveness. Journal of the International Neuropsychological Society, 13, 693-698.

Malloy-Diniz, L., Leite, W. B., Moraes, P. H. P., Corrêa, H., Bechara, A., \& Fuentes, D. (2008). Brazilian portuguese version of the Iowa Gambling Task: Transcultural adaptation and discriminant validity. Revista Brasileira de Psiquiatria, 30(2), 144-148.

Malloy-Diniz, L. F., Neves, F. S., Abrantes, S. S. C., Fuentes, D., \& Corrêa, H. (2009). Suicide behavior and neuropsychological assessment of type I bipolar patients. Journal of Affective Disorders, 112(1-3), 231-236.

Matsuo, K., Nicoletti, M. A., Peluso, M. A. M., Hatch, J. P., Nemoto, K., Watanabe, Y., et al. (2009). Anterior cingulate volumes associated with trait impulsivity in individuals with bipolar disorder. Bipolar Disorders, 11(6), 628-636.

Mazzola-Pomietto, P., Kaladjian, A., Azorin, J.-M., Anton, J.L., \& Jeanningros, R. (2009). Bilateral decrease in ventrolateral prefrontal cortex activation during motor response inhibition in mania. Journal of Psychiatric Research, 43(4), 432-441.

Moeller, F. G., Barratt, E. S., Dougherty, D. M., Schmitz, J. M., \& Swann, A. C. (2001). Psychiatry aspects of impulsivity. American Journal of Psychiatry, 158, 1783-1793.

Müller-Oerlinghausen, B., Berghöfer, A., \& Bauer, M. (2002). Bipolar Disorder. The Lancet, 359, 241-247.

Neves, F. S., Corrêa, H., \& Malloy-Diniz, L. (2009). Suicidal behavior in Bipolar Disorder: What is the influence of psychiatric comorbidities? Journal of Clinical Psychiatry, 70, 1-13.

Neves, F. S., Silveira, G., Romano-Silva, M. A., Malloy-Diniz, L., Ferreira, A. A., De Marco, L., et al. (2008). Is the 5HTTLPR polymorphism associated with Bipolar Disorder or with suicidal behavior of bipolar disorder patients? American Journal of Medical Genetics. Part B, Neuropsychiatric Genetics, 147B, 114-116.

Olley, A., Malhi, G. S., Mitchell, P. B., Batchelor, J., Lagopoulos, J., \& Austin, M.-P. V. (2005). When euthymia is just not good enough: The neuropsychology of bipolar disorder. The Journal of Nervous and Mental Disease, 193(5), 323-330. 
Moraes, P. H. P., Neves, F. S., Vasconcelos, A. G., Lima, I. M. M., Brancaglion, M., Sedyiama, C. Y., Fuentes, D., Romano-Silva, M. A., Corrêa, H. \& Malloy-Diniz, L. F.(2013). Relationship between Neuropsychological and Clinical Aspects and Suicide Attempts in Euthymic Bipolar Patients.

Oquendo, M. A., Currier, D., Liu, S.-M., Hasin, D. S., Grant, B. F., \& Blanco, C. (2010). Increased risk for suicidal behavior in comorbid bipolar disorder and alcohol use disorders: Results from the National Epidemiologic Survey on Alcohol and Related Conditions (NESARC). The Journal of Clinical Psychiatry, 71(7), 902-909.

Pattij, T., \& Vanderschuren, L. J. M. J. (2008). The neuropharmacology of impulsive behaviour. Trends in Pharmacological Sciences, 29(4), 192-199.

Patton, J. H., Stanford, M. S., \& Barratt, E. S. (1995). Factor structure of the Barratt Impulsiveness Scale. Journal of Clinical Psychology, 51(6), 768-774.

Rihmer, Z., \& Benazzi, F. (2010). Impact on suicidality of the borderline personality traits impulsivity and affective instability. Annals of Clinical Psychiatry, 22(2), 121-128.

Rogers, R. D., Tunbridge, E. M., Bhagwagar, Z., Drevets, W. C., Sahakian, B., \& Carter, C. S. (2003). Tryptophan depletion alters the decision-making of healthy volunteers through altered processing of reward cues. Neuropsychopharmacology, 28, 153-162.

Sagvolden, T., Johansen, E. B., Aase, H., \& Russell, V. A. (2005). A dynamic developmental theory of attention-deficit/ hyperactivity disorder (ADHD) predominantly hyperactive/ impulsive and combined subtypes. The Behavioral and Brain Sciences, 28(3), 397-419; discussion 419-468.

Selva, G., Salazar, J., Balanzá-Martínez, V., Martínez-Arán, A., Rubio, C., Daban, C., et al. (2007). Bipolar I patients with and without a history of psychotic symptoms: Do they differ in their cognitive functioning? Journal of Psychiatric Research, 41(3-4), 265-272.

Stanford, M. S., Mathias, C. W., Dougherty, D. M., Lake, S. L., Anderson, N. E., \& Patton, J. H. (2009). Fifty years of the Barratt Impulsiveness Scale: An update and review. Personality and Individual Differences, 47, 385-395.

Swann, A. C., Dougherty, D. M., Pazzaglia, P. J., Pham, M., Steinberg, J. L., \& Moeller, F. G. (2005). Increased impulsivity associated with severity of suicide attempt history in patients with bipolar disorder. The American Journal of Psychiatry, 162(9), 1680-1687.

Swann, A. C., Lijffijt, M., Lane, S. D., Steinberg, J. L., \& Moeller, F. G. (2009). Increased trait-like impulsivity and course of illness in bipolar disorder. Bipolar Disorders, 11(3), 280-288.

Swann, A. C., Steinberg, J. L., Lijffijt, M., \& Moeller, F. G. (2008). Impulsivity: Differential relationship to depression and mania in bipolar disorder. Journal of Affective Disorders, 106(3), 241-248.

Turecki, G. (2005). Dissecting the suicide phenotype: The role of impulsive-aggressive behaviours. Journal of Psychiatry and Neuroscience, 30(6), 398-408.

Zelazo, P. D., Craik, F. I. M., \& Booth, L. (2004). Executive function across the life span. Acta Psychologica, 115, 167183. 